\title{
Analgesic prescribing habits and patterns of Canadian chief urology residents: A national survey
}

\author{
Ali Dergham'; Greg Hosier²; Melanie Jaeger ${ }^{3}$; J. Curtis Nickel²; D. Robert Siemens²; Thomas \\ McGregor $^{2}$ \\ ${ }^{1}$ School of Medicine, Faculty of Health Sciences, Queen's University, Kingston, ON, Canada; ${ }^{2}$ Department of \\ Urology, Queen's University, Kingston, ON, Canada; ${ }^{3}$ Department of Anesthesiology and Perioperative Medicine, \\ Queen's University, Kingston, ON, Canada
}

Cite as: Can Urol Assoc J 2020 January 20; Epub ahead of print. http://dx.doi.org/10.5489/cuaj.6221

Published online January 20, 2020

$* * *$

\section{Abstract}

Introduction: Prior studies have identified significant knowledge gaps in acute and chronic pain management among graduating urology residents as of five years ago. Since then, there has been increasing awareness of the impact of excessive opioid prescribing on long-term narcotic use and development of adverse narcotic-related events. However, it is unclear whether the attitudes and experience of graduating urology residents have changed. We set out to evaluate the attitudes and experience of graduating urology residents in prescribing opioid/non-opioid analgesia for acute (AP), chronic non-cancer ( $\mathrm{CnC}$ ), and chronic cancer (CC) pain.

Methods: Graduating urology residents were surveyed at a review course in 2018. The survey consisted of open-ended and close-ended five-point Likert scale questions. Descriptive statistics, Mann-Whitney U-test, and Student's t-test were performed.

Results: A total of 32 PGY 5 urology residents completed our survey ( $92 \%$ response rate). The vast majority agreed that formal training in managing $\mathrm{AP} / \mathrm{CnC} / \mathrm{CC}$ to be valuable $(91 / 78 / 81 \%)$. Most find their training in $\mathrm{CnC} / \mathrm{CC}$ management to be inadequate and are unaware of any opioid prescribing guidelines; $66 \%$ never counsel patients on how to dispose of excess opioids. In general, $88 \%$ are comfortable prescribing opioids, whereas most are very uncomfortable prescribing cannabis or antidepressants $(100 \% / 78 \%)$. Residents reported the Acute Pain Service as the highest-rated resource for information, and dedicated textbooks the least.

Conclusions: This survey demonstrated that experience in pain management remains variable among urology residents. Knowledge gaps remain, particularly in the management of chronic cancer/non-cancer pain. 


\section{Introduction}

The "opioid crisis" in Canada, primarily a result of opioid over-prescribing, continues to exert its toll on public health. ${ }^{1-4}$ There has been over 8000 opioid-related deaths between January 2016 and September 2018, the most of which ( $>90 \%$ ) were accidental. ${ }^{3,5}$ At the center of this crisis is the excessive prescribing of opioids; a $140 \%$ increase in defined daily doses of opioids dispensed was recorded in the two-year period of 2013-15 compared to 2003-05. 3,6,7 Moreover, Canadians are not only prescribed more opioids, they're also increasingly prescribed stronger opioids; $57.3 \%$ of opioids prescribed in 2016 are strong opioids (fentanyl, hydromorphone, morphine, and oxycodone), compared to $52.2 \%$ in $2012 .^{8}$

In addition to pain and palliative care specialists, surgeons are among the highest prescribers of opioids; in the US, surgeons prescribe $10 \%$ of all opioids dispensed. ${ }^{9,10}$ Various US studies have shown that as high as $70 \%$ of post-operatively prescribed opioids are not used, making them available for potential misuse or abuse. ${ }^{10-19}$ Moreover, patients rarely dispose of unused opioids. ${ }^{20}$ In addition to post-operative pain, surgeons prescribe opioids for the management of chronic cancer and non-cancer pain. Urologists, in particular, manage chronic non-cancer pains such as chronic prostatitis/chronic pelvic syndrome, interstitial cystitis, chronic epididymitis, and orchiodynia, in addition to chronic cancer-related pain, acute renal colic pain, and pain occurring in an acute surgical setting. ${ }^{21-24}$

Similar to other surgical specialties, most opioid prescriptions written in academic centres are written by urologists in training, highlighting the importance of an in-depth understanding of pain management options. ${ }^{23-26}$ However, studies involving medical oncologists and surgeons demonstrated clear knowledge gaps. ${ }^{24,27,28}$ A recent survey of US surgical program directors found that only $20 \%$ of training programs have mandatory opioid prescribing education as part of their curriculum. ${ }^{26,29}$ Moreover, in a 2013 survey of Canadian urology chief residents, Pace et al found a significant difference of training experience in chronic and acute pain management, and poor apparent knowledge of opioid prescribing. ${ }^{24}$

Since 2013, there has been increasing awareness of the impact of excessive opioid prescribing on long-term narcotic use and development of adverse-narcotic related events. However, it is unclear whether the attitudes and experience of graduating urology residents have changed. With the increasing number of opioid-related deaths, and the shift towards a competency-based graduate medical education, we hypothesize that insight into these habits and patterns would offer a deeper understanding of the quality and type of education Canadian urology residents are provided, and prove highly beneficial in facilitating the development of educational curricula. ${ }^{30}$

For this reason, we set out to evaluate the attitudes and experience of graduating urology residents in prescribing opioid/non-opioid analgesia for acute (AP), chronic non-cancer $(\mathrm{CnC})$ and chronic cancer (CC) pain. 


\section{Methods}

Ethics approval was obtained from Queen's University institutional review board. 35 postgraduate year-5 (PGY-5) urology residents from training programs across Canada, participating in the annual Queen's Urology Exam Skills Test (QUEST) course, were invited to participate in this voluntary study. Primary and secondary outcomes of the survey were communicated to all invitees. Invitees were informed that participation and responses will not impact their academic standing or their performance in the review course.

The study employed a confidential and anonymous paper survey comprised of open and closeended questions (Appendix A). Residents were asked about their confidence, experience, and formal training in the management of acute and chronic pain as measured by a 5-point Likert scale. In addition, they were asked about resources most often used, and the complimentary services most often engaged. Moreover, respondents were presented with three hypothetical cases (AP, CC, and CnC; Appendix A) and asked to fill an appropriate prescription.

Descriptive statistics was used to describe the data. Average Likert scores and standard deviations were calculated for all close-ended questions. In addition, an agreeableness score (percentage of participants selecting 4 or 5 on a 5-point Likert scale) were calculated. Written opioid prescriptions were analyzed and normalized to Morphine Equivalents per Day and compared on such basis. Moreover, statistical analysis involved Mann-Whitney U test, student's t-test, Pearson's Chi-squared test, or Fisher's exact test, as applicable.

\section{Results}

35 PGY-5 urology residents participating in QUEST were invited to complete our survey; 32 responses were collected, resulting in a response rate of $92 \%$. Fig. 1 summarizes the reported confidence, training and experience respondents have in managing different types of pain. Although only $63 \%$ report receiving formal training in the management of AP (mean Likert score $3.34 \pm 1.05 \mathrm{SD})$, most of the respondents $(81 \% ; 3.97 \pm 0.85)$ agree that their training in the managing of AP is adequate. On the other hand, only $19 \%(2.50 \pm 0.83 ; p<0.0001)$ and $22 \%$ $(2.53 \pm 0.93 ; \mathrm{p}<0.0001)$ of the residents thought their training in managing $\mathrm{CnC}$ and $\mathrm{CC}$, respectively, was adequate. This is in line with only $31 \%(2.75 \pm 1.0 ; 2.69 \pm 0.95)$ reporting receiving formal training in the management of $\mathrm{CnC}$ and $\mathrm{CC}$, respectively. Interestingly, the majority of respondents agree that formal training in the management of $\mathrm{AP}, \mathrm{CnC}$, and $\mathrm{CC}$ is very valuable.

In a similar fashion to the 2013 study by Pace et al, residents were asked to rank the resources they most often use in pain management (Fig. 2). ${ }^{24}$ Similar to previous studies, our results indicate that the acute pain service (APMS) and fellow trainees rank among the highest of values resources. On the other hand, guidelines and textbooks ranked among the lowest. In fact, only $19 \%$ are aware of any guidelines for the management of AP, and even fewer are aware of any guidelines for the management of $\mathrm{CC}(9 \%)$ or $\mathrm{CnC}(6 \%)$. 
When asked about confidence in prescribing different drug modalities (

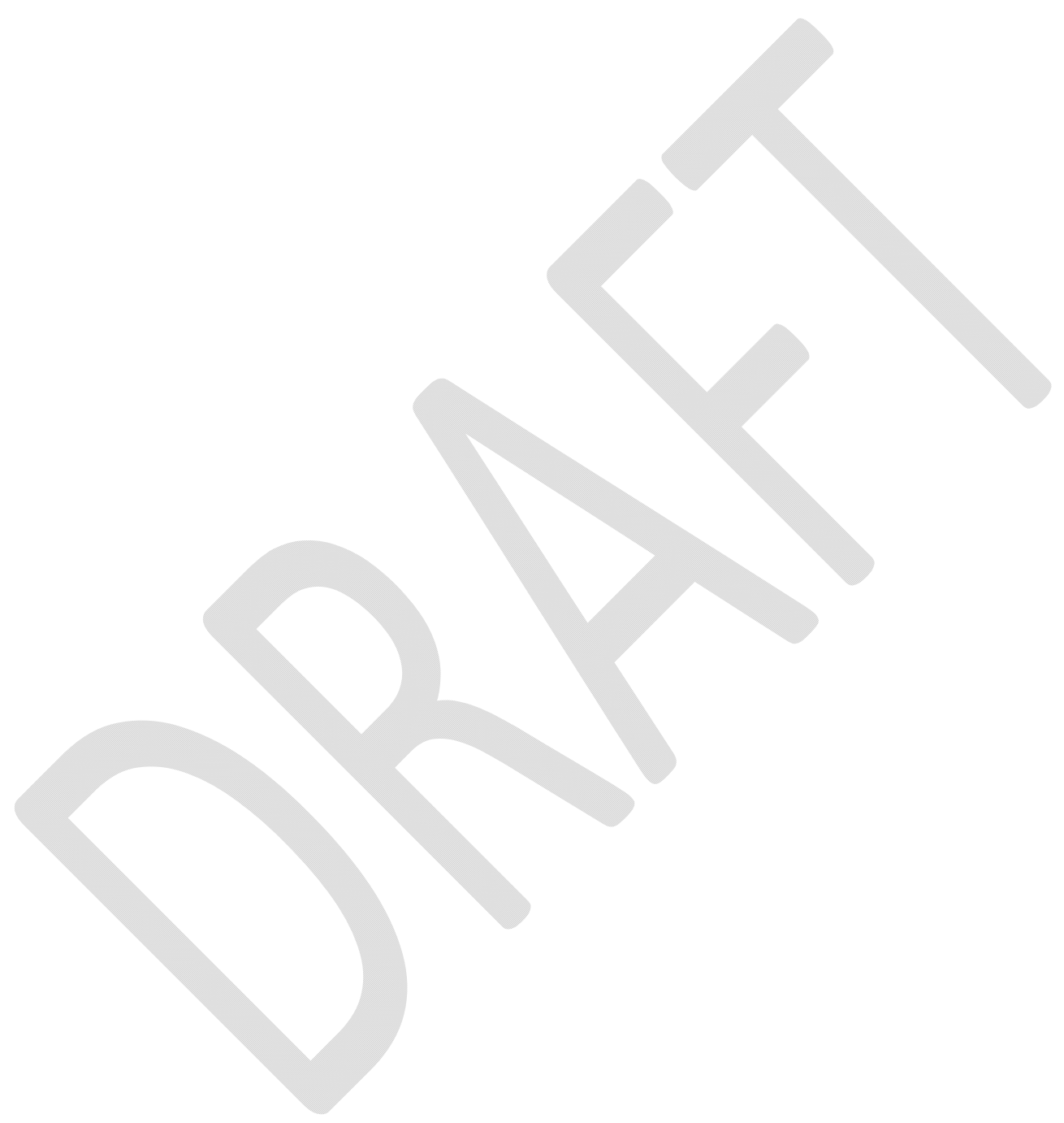


Fig. 3), the majority report comfort in prescribing acetaminophen, NSAIDs, and opioids. On the contrary, only $38 \%(3.16 \pm 1.00)$ agree that they're comfortable prescribing gabapentinoids. Even fewer $(3 \% ; 2.16 \pm 0.83)$ feel confident prescribing muscle relaxants and none of the respondents feel comfortable prescribing antidepressants or medicinal marijuana $(1.75 \pm 0.79$ and $1.28 \pm 0.45$, respectively). $45 \%$ (3.16 \pm 1.25$)$ indicated regularly engaging complimentary services for pain control, with palliative care and acute pain service being the two most frequently consulted services (63\% and 53\%, respectively).

The residents were presented with three hypothetical cases and asked to write appropriate prescriptions and list the most pertinent issues they would counsel on (

Fig. 4). Scripts for the AP case had a median of 2.5 drugs, with $72 \%$ containing an NSAID, followed by $\alpha$-blockers (63\%), and opioids (56\%). The three items most often counseled for on an AP script were constipation, dizziness, and gastrointestinal (GI) bleeds (69\%, 34\%, and 34\%, respectively). Greater variability was seen in the $\mathrm{CnC}$ scripts, where the most common drug class prescribed was NSAIDs (38\% of prescriptions). Tricyclic antidepressants, acetaminophen, and opioids appeared in similar frequencies $(29 \%, 25 \%$, and $21 \%$, respectively). Constipation and GI bleeds were again the items most counseled for (29\% each), followed by drowsiness (17\%). CnC prescriptions had a median of $1 \mathrm{drug} / \mathrm{script}$. CC scripts had the highest frequency of opioid prescriptions, with $91 \%$ of respondents prescribing some form of opioid, followed by acetaminophen and a laxative (31\% and $28 \%$, respectively). $88 \%$ of respondents listed constipation as an item for counselling; interestingly, addiction was only mentioned by $25 \%$ of respondents, following drowsiness (28\%). When asked explicitly, $85 \%$ of respondents said they never or seldom counsel for proper opioid disposal. Moreover, in order to facilitate comparison, all opioid prescriptions were normalized to Morphine Equivalents per day ( 
Fig. 5). Not only were opioids prescribed more often for $\mathrm{CC}$, the amount of opioid prescribed $(50 \pm 29 \mathrm{mg} /$ day $)$ was significantly greater than that of AP scripts $(35 \pm 26 \mathrm{mg} / \mathrm{day} ; \mathrm{p}=0.032)$ and $\mathrm{CnC}$ scripts $(8 \pm 18 \mathrm{mg} /$ day; $\mathrm{p}<0.00001)$.

\section{Discussion}

In the United States alone, more than 130 people die every day from overdosing on opioids. ${ }^{31}$ Liberal prescribing of opioids by well-meaning physicians has had a significant role in this crisis through misuse and diversion. ${ }^{32}$ More recently, there has been increasing awareness of the harms of medical prescribing of opioids, which has brought the issue of pain management to the forefront for all health practitioners, including urologists. A 2013 survey of Canadian chief Urology residents identified a knowledge gap in managing different types of pain, and recommended an increased focus on pain management during residency education. ${ }^{24}$ Our results show that despite increasing awareness of this issue, little has changed over 5 years in the attitudes and experience of Canadian urology residents regarding pain management.

Although the vast majority of residents agreed that formal training in pain management was important, it represents a disproportionately small percentage of the curriculum in urological postgraduate education according to this survey. When probed about educational resources used for pain management, the most commonly cited resource remained the acute pain service. The involvement of acute pain services may represent a double-edged sword, as surgical residents can learn passively from suggestions of the consulting service but may have their active involvement in acute pain management diminish. Encouragingly, since 2013, residents reported a greater dependence on online resources, which makes for more active, albeit informal, learning. Interestingly, though residents reported comfort in prescribing a variety of analgesic agents, many indicated a lack of confidence particularly in prescribing gabapentinoids and TCAs, which have become common adjuncts to the traditional opioid and NSAID pain regimes in the inpatient and outpatient setting.

Unsurprisingly, residents reported less comfort managing chronic cancer and non-cancer pain. Although chronic cancer and non-cancer pain are less commonly dealt with by urologists, there remain several conditions in which urologists may be called upon to prescribe pain medications in these settings. Our index patient for chronic cancer pain in our survey was a patient with metastatic prostate cancer. The urologist is often the primary specialist involved with caring for these patients. This may lead to urologists taking a more central role in pain management in this setting. Our index patient with chronic non-cancer pain, was a patient with interstitial cystitis bladder pain syndrome. This represents another condition that is commonly managed by the urologist, in which experience with chronic non-cancer pain management may be useful.

Since the time of publication of the 2013 survey, various pain management guidelines have been published, with the Canadian Guideline for Opioids for Non-Cancer Pain being one of the 
more recent ones. ${ }^{33-37}$ Despite that, very few residents were aware of any guidelines; in fact, guidelines ranked as one of the least-employed resource among residents. Although most respondents prescribed opioids for CC pain, only $25 \%$ of them mentioned addiction as an item they'd counsel on, and most indicated never/seldomly counselling on opioid disposal. This is problematic as diversion is common; the nonmedical use of prescription opioids among US adults was $4.9 \%$ in $2013 .{ }^{37}$

Our results show that pain management should become a formal component of the academic curriculum for urology residents, complimenting the current experiential-based approach. This would help ensure that future consultants are confident to manage these often complex problems. Recognizing the importance of pain management training, the 2019 Accreditation Council for Graduate Medical Education (ACGME) program requirements for Graduate Medical Education in Urology now contain specific items requiring programs to provide instruction and experience in pain management, with a focus on signs of addiction (requirement IV.C.2). ${ }^{38}$

This study has several limitations inherent to a study design involving a survey of a captured audience. This survey focused on urologist and clinical scenarios within this specialty, and hence, results may not extrapolate to other subspecialties. However, similar knowledge gaps have been identified in other specialties and other countries. ${ }^{39-41}$ Secondly, this survey represents only a snapshot of self-reported attitudes and experience of pain management within their training. However, these residents were chosen close to completion of their training to ensure that they had experienced all rotations and educational curricula set out by their respective programs. Thirdly, this was a somewhat small sample size. However, the response rate of the residents and the consistency of responses throughout the survey attests to the robustness of the results and interpretation.

\section{Conclusions}

This survey demonstrated that experience in pain management remains variable among urology residents. Formal training in pain management remains a disproportionately small percentage of post-graduate urology training. Although residents reported adequate experience in managing AP, reported confidence in management of chronic cancer and non-cancer pain as well as comfort using a variety of analgesic agents was low. Resources used remain mostly unchanged from 2013, apart from greater dependence on online resources. 


\section{References}

1. Fischer, B., Rehm, J. \& Tyndall, M. Effective Canadian policy to reduce harms from prescription opioids: learning from past failures. CMAJ 188, 1240-1244 (2016).

2. Fischer, B., Vojtila, L. \& Rehm, J. The 'fentanyl epidemic' in Canada - Some cautionary observations focusing on opioid-related mortality. Prev Med 107, 109-113 (2018).

3. Fischer, B., Varatharajan, T., Shield, K., Rehm, J. \& Jones, W. Crude estimates of prescription opioid-related misuse and use disorder populations towards informing intervention system need in Canada. Drug and Alcohol Dependence 189, 76-79 (2018).

4. Gladstone, E. J., Smolina, K., Weymann, D., Rutherford, K. \& Morgan, S. G. Geographic Variations in Prescription Opioid Dispensations and Deaths Among Women and Men in British Columbia, Canada. Med Care 53, 954-959 (2015).

5. Special Advisory Committee on the Epidemic of Opioid Overdoses. National report: Apparent opioid-related deaths in Canada (January 2016 to March 2018). (Public Health Agency of Canada, 2018).

6. International Narcotics Control Board. Narcotic Drugs - Estimated World Requirements for 2007 (Statistics for 2005). (United Nations, 2007).

7. International Narcotics Control Board. Narcotic Drugs - Estimated World Requirements for 2017 (Statistics for 2015). (United Nations, 2017).

8. Canadian Institute for Health Information. Opioid prescriptions rising in Canada, but quantity prescribed declining. (2017). Available at: https://www.cihi.ca/en/opioidprescriptions-rising-in-canada-but-quantity-prescribed-declining. (Accessed: 13th January 2019)

9. Levy, B., Paulozzi, L., Mack, K. A. \& Jones, C. M. Trends in Opioid AnalgesicPrescribing Rates by Specialty, U.S., 2007-2012. American Journal of Preventive Medicine 49, 409-413 (2015).

10. Eid, A. I. et al. Variation of Opioid Prescribing Patterns among Patients undergoing Similar Surgery on the Same Acute Care Surgery Service of the Same Institution: Time for Standardization? Surgery 164, 926-930 (2018).

11. Bates, C., Laciak, R., Southwick, A. \& Bishoff, J. Overprescription of Postoperative Narcotics: A Look at Postoperative Pain Medication Delivery, Consumption and Disposal in Urological Practice. The Journal of Urology 185, 551-555 (2011).

12. Ringwalt, C. et al. Differential Prescribing of Opioid Analgesics According to Physician Specialty for Medicaid Patients with Chronic Noncancer Pain Diagnoses. Pain Research and Management (2014). doi:10.1155/2014/857952

13. Morris, B. J. \& Mir, H. R. The opioid epidemic: impact on orthopaedic surgery. J Am Acad Orthop Surg 23, 267-271 (2015).

14. Blay, E. et al. Variation in post-discharge opioid prescriptions among members of a surgical team. The American Journal of Surgery 216, 25-30 (2018).

15. Kumar, K. et al. Unused Opioid Pills After Outpatient Shoulder Surgeries Given Current Perioperative Prescribing Habits. Am J Sports Med 45, 636-641 (2017).

16. Rodgers, J., Cunningham, K., Fitzgerald, K. \& Finnerty, E. Opioid consumption following outpatient upper extremity surgery. J Hand Surg Am 37, 645-650 (2012). 
17. Mutlu, I., Abubaker, A. O. \& Laskin, D. M. Narcotic prescribing habits and other methods of pain control by oral and maxillofacial surgeons after impacted third molar removal. J. Oral Maxillofac. Surg. 71, 1500-1503 (2013).

18. Hill, M. V., Stucke, R. S., Billmeier, S. E., Kelly, J. L. \& Barth, R. J. Guideline for Discharge Opioid Prescriptions after Inpatient General Surgical Procedures. Journal of the American College of Surgeons 226, 996-1003 (2018).

19. Kim, N. et al. A Prospective Evaluation of Opioid Utilization After Upper-Extremity Surgical Procedures: Identifying Consumption Patterns and Determining Prescribing Guidelines. J Bone Joint Surg Am 98, e89 (2016).

20. Buffington, D. E., Lozicki, A., Alfieri, T. \& Bond, T. C. Understanding factors that contribute to the disposal of unused opioid medication. J Pain Res 12, 725-732 (2019).

21. Nickel, J. C. et al. Diagnosis and treatment of prostatitis in Canada. Urology 52, 797-802 (1998).

22. Nickel, J. C., Teichman, J. M. H., Gregoire, M., Clark, J. \& Downey, J. Prevalence, diagnosis, characterization, and treatment of prostatitis, interstitial cystitis, and epididymitis in outpatient urological practice: the Canadian PIE Study. Urology 66, 935940 (2005).

23. Levy, M. H. Pharmacologic treatment of cancer pain. N. Engl. J. Med. 335, 1124-1132 (1996).

24. Pace, J., Jaeger, M., Nickel, J. C. \& Siemens, D. R. Pain management in urology training: A national survey of senior residents. Canadian Urological Association Journal 7, 456 (2013).

25. Alameddine, M. et al. Surgeon Attitudes Towards Prescribing Opioids. (2016).

26. Yorkgitis, B. K. et al. Opioid Prescribing Education in Surgical Residencies: A Program Director Survey. Journal of Surgical Education 75, 552-556 (2018).

27. Breuer, B., Fleishman, S. B., Cruciani, R. A. \& Portenoy, R. K. Medical oncologists' attitudes and practice in cancer pain management: a national survey. J. Clin. Oncol. 29, 4769-4775 (2011).

28. Gallagher, R., Hawley, P. \& Yeomans, W. A survey of cancer pain management knowledge and attitudes of British Columbian physicians. Pain Res Manag 9, 188-194 (2004).

29. Olsen, K. R. et al. Postoperative surgical trainee opioid prescribing practices (POST OPP): an institutional study. Journal of Surgical Research 229, 58-65 (2018).

30. Pinsk, M., Karpinski, J. \& Carlisle, E. Introduction of Competence by Design to Canadian Nephrology Postgraduate Training. Can J Kidney Health Dis 5, 2054358118786972 (2018).

31. Centre for Disease Control and Prevention. CDC WONDER. (2019). Available at: https://wonder.cdc.gov/. (Accessed: 29th July 2019)

32. Van Zee, A. The Promotion and Marketing of OxyContin: Commercial Triumph, Public Health Tragedy. Am J Public Health 99, 221-227 (2009).

33. Cox, A. et al. CUA guideline: Diagnosis and treatment of interstitial cystitis/ bladder pain syndrome. Canadian Urological Association Journal 10, 136 (2016).

34. Jarvi, K. A. et al. Canadian Urological Association best practice statement on chronic scrotal pain. Canadian Urological Association Journal 12, (2018). 
35. Ordon, M. et al. Canadian Urological Association Guideline: Management of Ureteral Calculi. 38

36. Hanno, P. M. et al. American Urological Association (AUA) Guideline. 45 (2014).

37. Busse, J. The 2017 Canadian Guideline for Opioids for Chronic Non-Cancer Pain. Cancer Pain 105 (2017).

38. ACGME. Common Program Requirements. 58

39. Ger, L. P., Ho, S. T. \& Wang, J. J. Physicians' knowledge and attitudes toward the use of analgesics for cancer pain management: a survey of two medical centers in Taiwan. $J$ Pain Symptom Manage 20, 335-344 (2000).

40. Scanlon, M. N. \& Chugh, U. Exploring physicians' comfort level with opioids for chronic noncancer pain. Pain Res Manag 9, 195-201 (2004).

41. McDonald, F. S., Zeger, S. L. \& Kolars, J. C. Factors associated with medical knowledge acquisition during internal medicine residency. J Gen Intern Med 22, 962-968 (2007). 


\section{Figures and Tables}

Fig. 1. Reported overall comfort and experience in managing acute pain, chronic non-cancer pain, and chronic cancer.

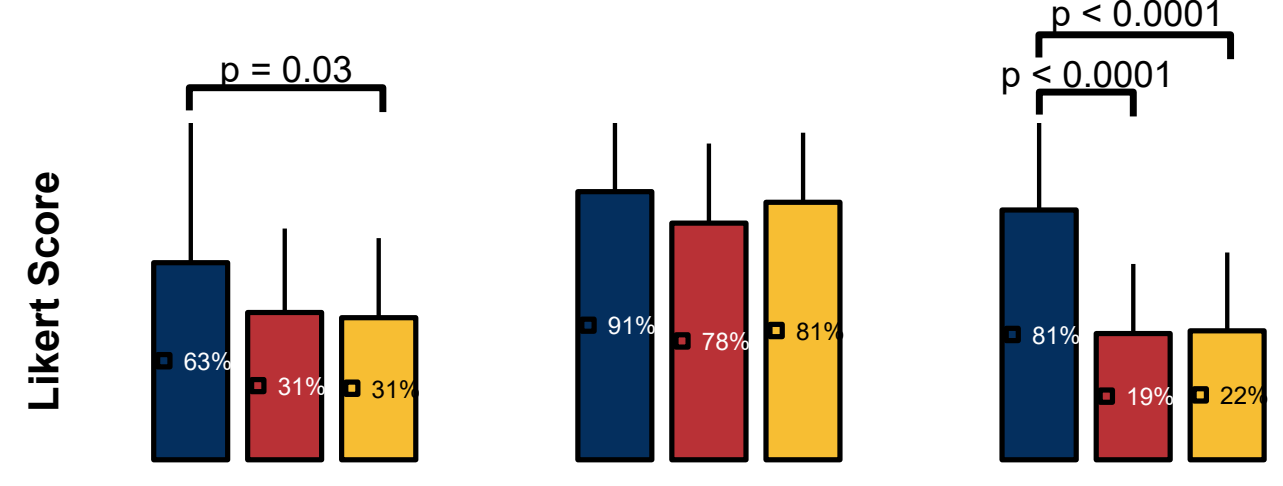

Acute Pain $\quad \square$ Chronic Non-Cancer $\quad$ Chronic Cancer

Fig. 2. Educational resources used. Box and whisker plot (mean, 95\% confidence limit) of ranking scores.

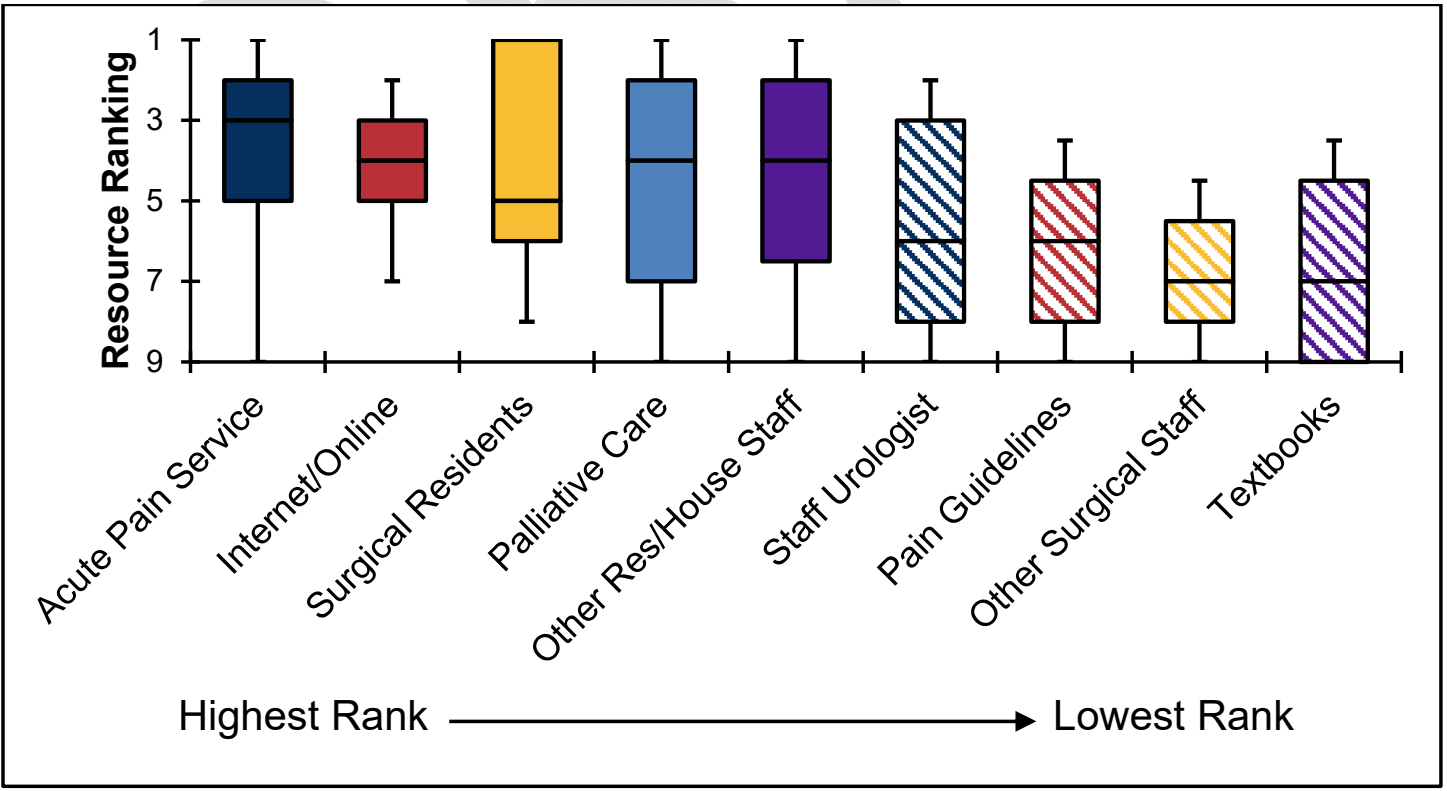


Fig. 3. Reported comfort level prescribing different drug modalities.

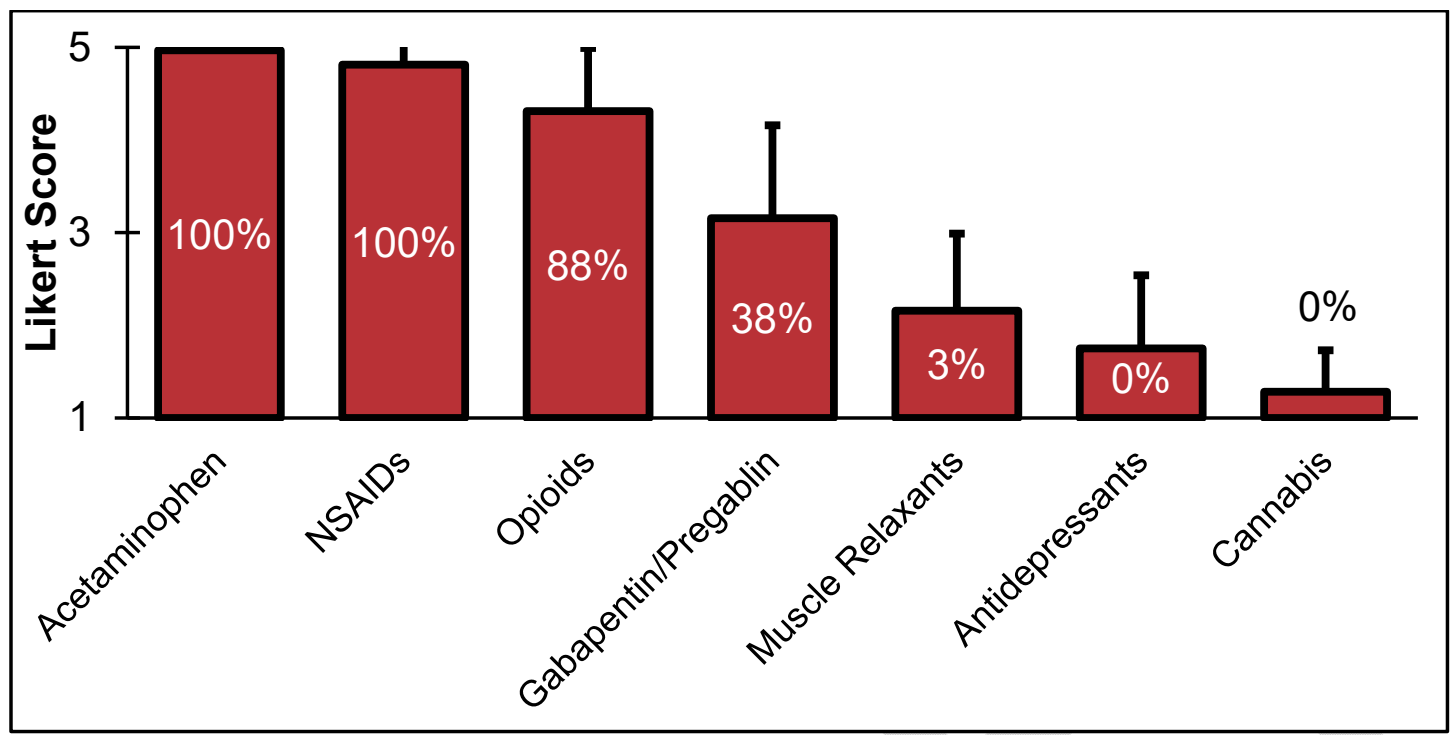

Fig. 4. Breakdown of hand-filled prescriptions.

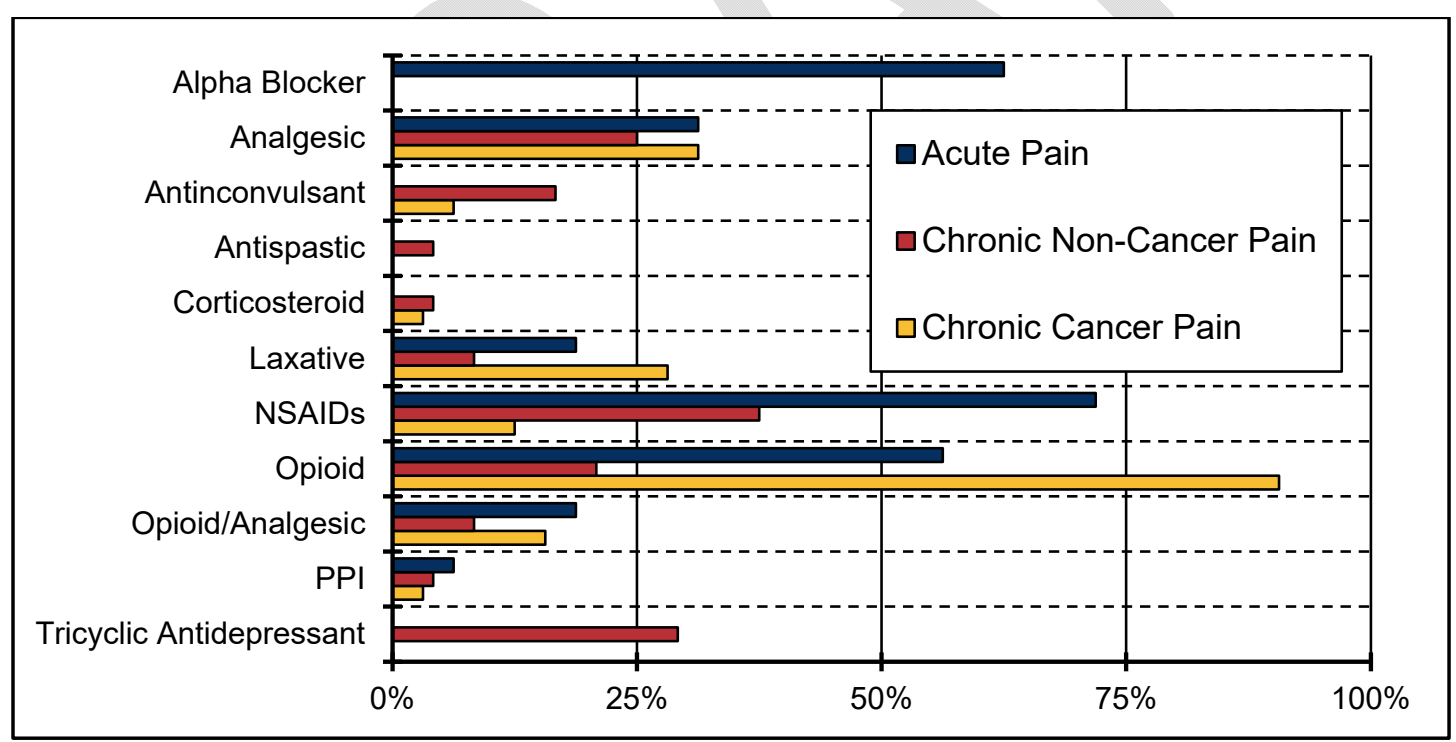


Fig. 5. Amount of opioid dispensed per prescription.

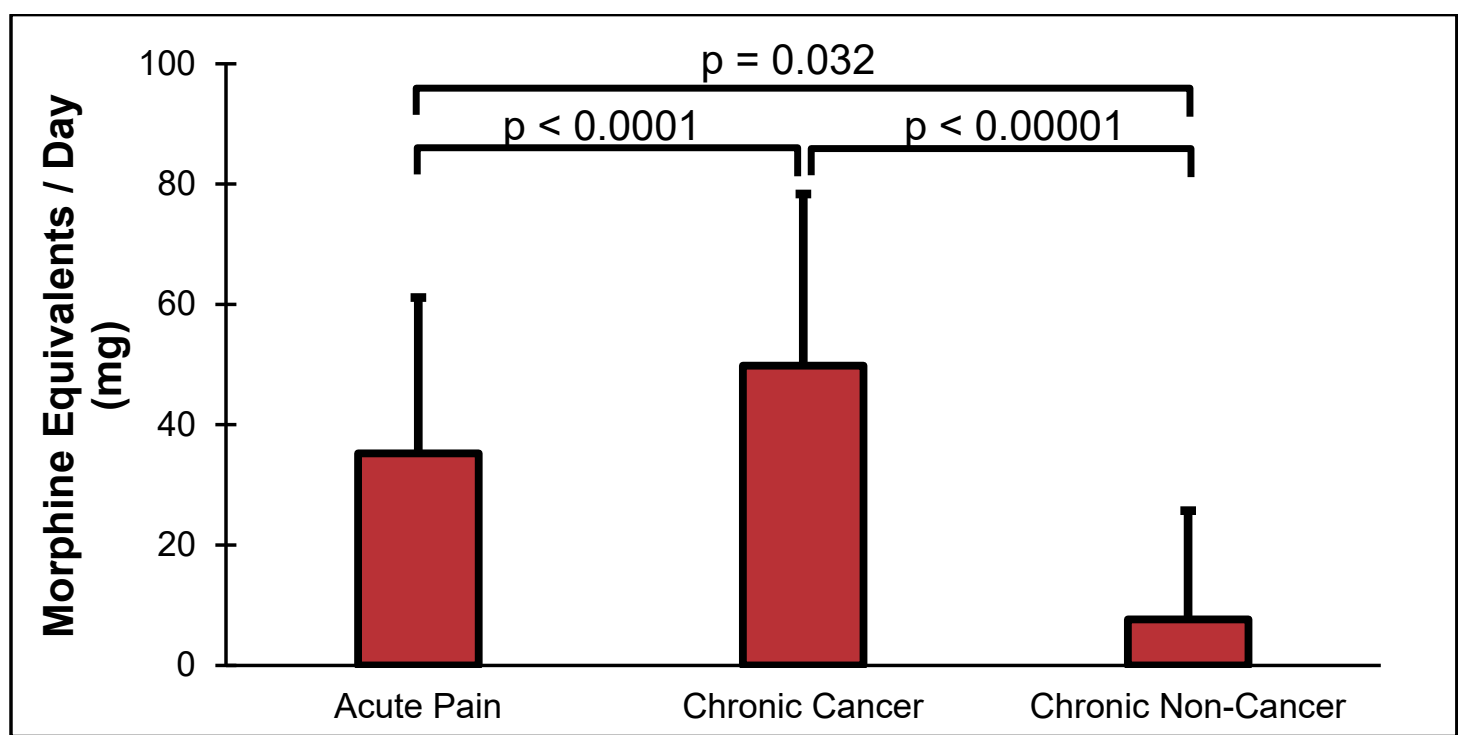




\author{
Appendix A. Analgesic prescribing habits and patterns of Canadian urology residents \\ Primary Investigators: D. Robert Siemens, MD, FRCSC; Thomas McGregor, MD, FRCSC \\ Dear QUEST participant,
}

We invite to complete the following survey dealing with analgesic prescribing habits and patterns of Canadian urology residents. We hope that our findings would offer a deeper understanding of the quality and type of education Canadian urology residents are provided and prove highly beneficial in curricula development.

Your participation in this survey is completely voluntary and anonymous. Completing this survey, or not, will have no impact on your academic standing. Moreover, we're collecting no identifying data aside from region of Canada currently training in (Western, Central, Eastern). The survey results will by the investigators, and possibly by Research Ethics Board representatives for auditing and quality assurance purposes.

For ethics concerns, please contact the Queen's University Health Sciences and Affiliated Teaching Hospitals Research Ethics Board. Call 1-844-535-2988 (toll free in North America) or email the HSREB Chair at: clarkaf@queensu.ca.

Thank you for your participation,

Thomas McGregor

Victory 4, KGH

Kingston, Ontario

K7L 2V7

613-548-2437 


\section{Analgesic prescribing habits and patterns of Canadian urology residents}

This voluntary and anonymous survey aims to gain insight into the pain management strategies and prescribing habits of Canadian urology residents. We hope that this would offer a deeper understanding of the quality and type of education Canadian urology residents are provided and prove highly beneficial in curricula development. We're collecting no identifying data aside from region of Canada currently training in (Western, Central, Eastern).

* Required

1. What year of residency are you in? *

Mark only one oval.

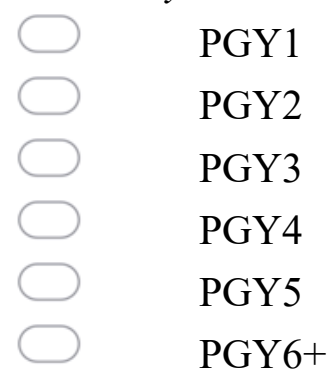

2. In which area are you currently completing your residency?

Mark only one oval.

$\begin{array}{ll} & \text { West (BC, AB, SK) } \\ & \text { Central (MB, ON) } \\ & \text { East (QC, NB, NL, NS, PE) } \\ & \text { USA } \\ \text { International }\end{array}$

3. During my residency training, I have received formal training/teaching in the following: $*$ Mark only one circle per row.

\begin{tabular}{llllll} 
& $\begin{array}{l}\text { Strongly } \\
\text { Disagree }\end{array}$ & Disagree & Undecided & Agree & $\begin{array}{l}\text { Strongly } \\
\text { Agree }\end{array}$ \\
\hline Acute Pain & $\mathrm{O}$ & $\mathrm{O}$ & $\mathrm{O}$ & 0 & $\mathrm{O}$ \\
\hline $\begin{array}{l}\text { Chronic } \\
\text { Non-Cancer Pain }\end{array}$ & $\mathrm{O}$ & $\mathrm{O}$ & $\mathrm{O}$ & 0 & 0 \\
\hline $\begin{array}{l}\text { Chronic Cancer } \\
\text { Pain }\end{array}$ & $\mathrm{O}$ & $\mathrm{O}$ & $\mathrm{O}$ & 0 & 0 \\
\hline
\end{tabular}


4. Within Urology, formal training in management of the following would be/is very valuable: * Mark only one circle per row.

\begin{tabular}{llllll} 
& $\begin{array}{l}\text { Strongly } \\
\text { Disagree }\end{array}$ & Disagree & Undecided & Agree & $\begin{array}{l}\text { Strongly } \\
\text { Agree }\end{array}$ \\
\hline Acute Pain & O & O & O & O & O \\
\hline $\begin{array}{l}\text { Chronic } \\
\text { Non-Cancer Pain }\end{array}$ & O & 0 & 0 & 0 & 0 \\
\hline $\begin{array}{l}\text { Chronic Cancer } \\
\text { Pain }\end{array}$ & O & 0 & 0 & 0 & 0 \\
\hline
\end{tabular}

5. I feel my training (formal or informal) and experience in managing the following to be adequate: *

Mark only one circle per row.

\begin{tabular}{llllll} 
& $\begin{array}{l}\text { Strongly } \\
\text { Disagree }\end{array}$ & Disagree & Undecided & Agree & $\begin{array}{l}\text { Strongly } \\
\text { Agree }\end{array}$ \\
\hline Acute Pain & $\mathrm{O}$ & $\mathrm{O}$ & $\mathrm{O}$ & 0 & $\mathrm{O}$ \\
\hline $\begin{array}{l}\text { Chronic } \\
\text { Non-Cancer Pain }\end{array}$ & $\mathrm{O}$ & $\mathrm{O}$ & 0 & 0 & 0 \\
\hline $\begin{array}{l}\text { Chronic Cancer } \\
\text { Pain }\end{array}$ & $\mathrm{O}$ & 0 & 0 & 0 & 0 \\
\hline
\end{tabular}

6. I am aware of peer reviewed opioid prescribing guidelines for the management of: * Mark only one circle per row.

\begin{tabular}{llllll} 
& $\begin{array}{l}\text { Strongly } \\
\text { Disagree }\end{array}$ & Disagree & Undecided & Agree & $\begin{array}{l}\text { Strongly } \\
\text { Agree }\end{array}$ \\
\hline Acute Pain & $\mathrm{O}$ & $\mathrm{O}$ & $\mathrm{O}$ & $\mathrm{O}$ & $\mathrm{O}$ \\
\hline $\begin{array}{l}\text { Chronic } \\
\text { Non-Cancer Pain }\end{array}$ & $\mathrm{O}$ & $\mathrm{O}$ & $\mathrm{O}$ & $\mathrm{O}$ & $\mathrm{O}$ \\
\hline $\begin{array}{l}\text { Chronic Cancer } \\
\text { Pain }\end{array}$ & $\mathrm{O}$ & $\mathrm{O}$ & $\mathrm{O}$ & $\mathrm{O}$ & $\mathrm{O}$ \\
\hline
\end{tabular}

7. Please rank the following people/services that were the greatest resource for your education in pain management (1: highest, 9: lowest) *

\section{Rank}

Acute Pain Service (Anesthesiologist) 
Dedicated Textbooks

Staff Urologist

Other Surgical Staff

Surgical Residents

Pain Guidelines

Palliative Care Service

Other Residents/House-staff 
For each of the following cases, please write a prescription for the medication(s) you would typically give for symptom management in each scenario. Please write the prescription in the same style/format you would typically use in a real-life scenario.

A 35-year-old healthy male assessed in the emergency room and found to have a $4 \mathrm{~mm}$ left midureteric stone and 7/10 pain. Vital signs are stable, renal function is normal and there are no signs of infection. They wish to try to pass the stone at home.

R

DATE

8. Please list the TOP THREE (3) issues/side effects/concerns that you'd counsel the above patient on regarding their prescription: *

1.

2.

3. 
A 70-year-old man with CRPC presents with several painful symptomatic bone mets. He is awaiting appointments with radiation oncology and medical oncology. Please write a prescription for pain management for this patient.
R
DATE

9. Please list the TOP THREE (3) issues/side effects/concerns that you'd counsel the above patient on regarding their prescription: *

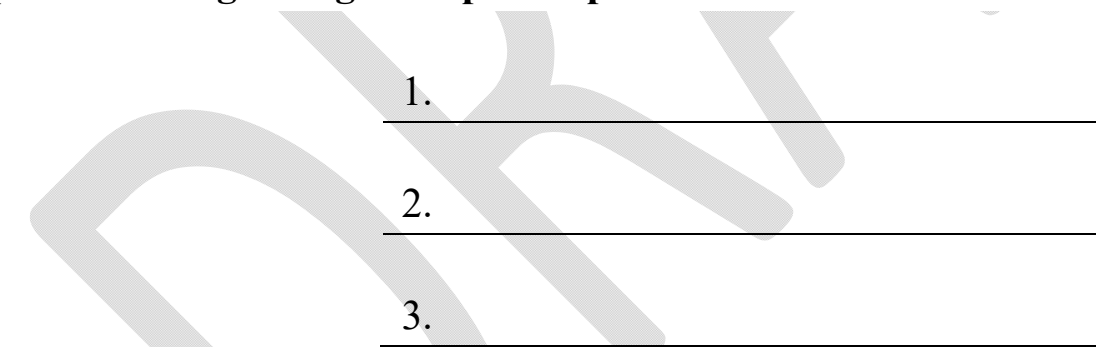


A 45-year-old women with interstitial cystitis bladder pain syndrome refractory to elmiron, mirabegron, intra-vesical DMSO presents with significant chronic pelvic discomfort. She describes the pain as 8 out of 10 and is requesting a medication(s) to ease the discomfort.

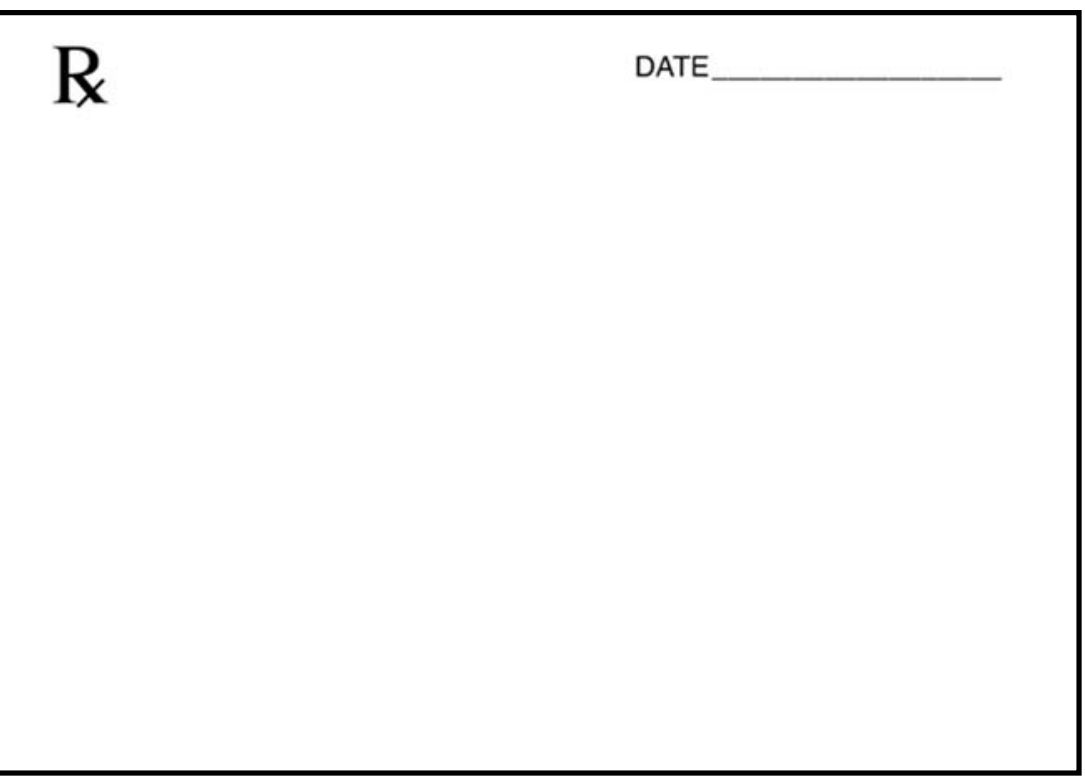

10. Please list the TOP THREE (3) issues/side effects/concerns that you'd counsel the above patient on regarding their prescription: *

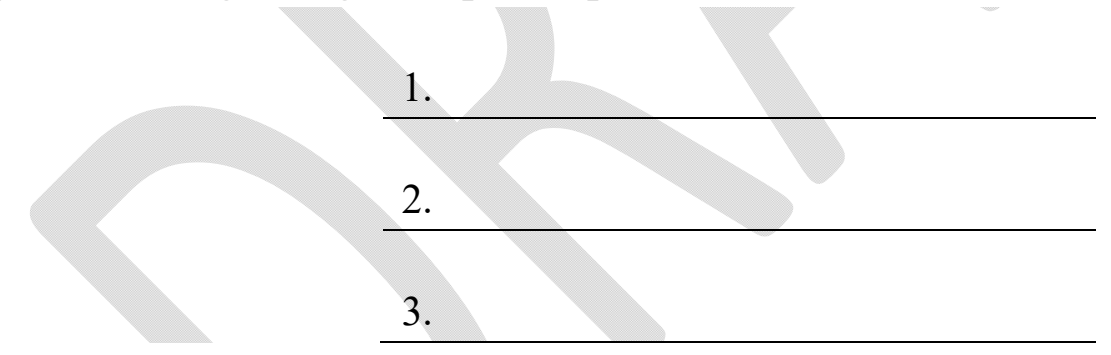


11. How often do you promote alternative, non-narcotic methods for the control of: * Mark only one circle per row.

\begin{tabular}{llllll} 
& Never & Seldom & $\begin{array}{l}\text { About Half } \\
\text { the Time }\end{array}$ & Usually & Always \\
\hline Acute Pain & $\mathrm{O}$ & $\mathrm{O}$ & $\mathrm{O}$ & $\mathrm{O}$ & $\mathrm{O}$ \\
\hline $\begin{array}{l}\text { Chronic } \\
\text { Non-Cancer Pain }\end{array}$ & $\mathrm{O}$ & $\mathrm{O}$ & $\mathrm{O}$ & 0 & $\mathrm{O}$ \\
\hline $\begin{array}{l}\text { Chronic Cancer } \\
\text { Pain }\end{array}$ & $\mathrm{O}$ & $\mathrm{O}$ & $\mathrm{O}$ & $\mathrm{O}$ & $\mathrm{O}$ \\
\hline $\begin{array}{l}\text { List the various } \\
\text { alternatives you } \\
\text { would advise the } \\
\text { patient to use : }\end{array}$ & & & & & \\
\hline
\end{tabular}

12. How often is medical marijuana prescribed AT YOUR INSTITUTION for the control of: *

Mark only one circle per row.

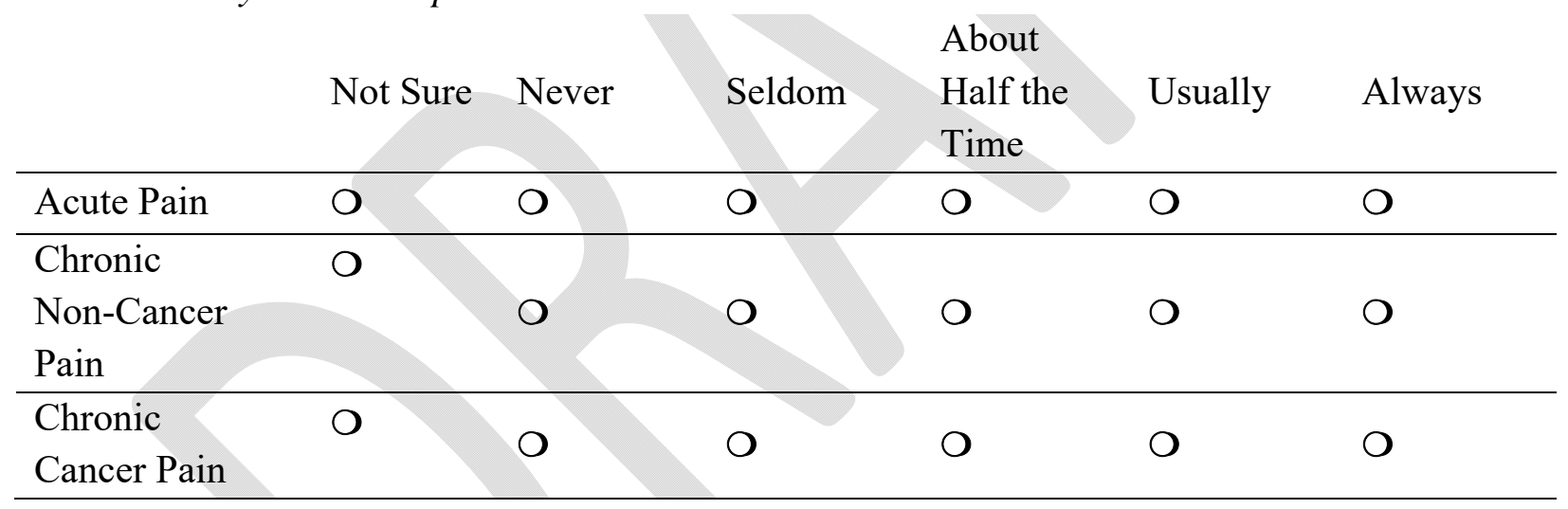

13. How often do you engage complimentary services for pain control? * Mark only one circle.

\begin{tabular}{lllllll} 
& 1 & 2 & 3 & 4 & 5 & \\
\hline Never & $\mathrm{O}$ & $\mathrm{O}$ & $\mathrm{O}$ & $\mathrm{O}$ & $\mathrm{O}$ & Always \\
\hline
\end{tabular}

14. What are the complimentary services often engaged at your institution? *

1.

2. 
3.

15. How often do you counsel your patients on how to properly dispose of excess opioids? * Mark only one circle.

\begin{tabular}{lllllll} 
& 1 & 2 & 3 & 4 & 5 & \\
\hline \multirow{2}{*}{ Never } & 0 & 0 & 0 & 0 & 0 & Always \\
\hline
\end{tabular}

16. How comfortable are you in prescribing each of the following pain medications: * Mark only one circle per row.

\begin{tabular}{llllll} 
& $\begin{array}{l}\text { Very } \\
\text { Uncomfortable }\end{array}$ & Uncomfortable & Neutral & Comfortable & $\begin{array}{l}\text { Very } \\
\text { Comfortable }\end{array}$ \\
\hline Antidepressants & $\mathrm{O}$ & $\mathrm{O}$ & $\mathrm{O}$ & $\mathrm{O}$ & $\mathrm{O}$ \\
\hline Muscle Relaxants & $\mathrm{O}$ & $\mathrm{O}$ & $\mathrm{O}$ & $\mathrm{O}$ & $\mathrm{O}$ \\
\hline Acetaminophen & $\mathrm{O}$ & $\mathrm{O}$ & $\mathrm{O}$ & $\mathrm{O}$ & $\mathrm{O}$ \\
\hline NSAIDs & $\mathrm{O}$ & $\mathrm{O}$ & $\mathrm{O}$ & $\mathrm{O}$ & $\mathrm{O}$ \\
\hline Gabapentin/Pregablin & $\mathrm{O}$ & $\mathrm{O}$ & $\mathrm{O}$ & $\mathrm{O}$ & $\mathrm{O}$ \\
\hline Cannabis & $\mathrm{O}$ & $\mathrm{O}$ & $\mathrm{O}$ & $\mathrm{O}$ & $\mathrm{O}$ \\
\hline Opioids & $\mathrm{O}$ & $\mathrm{O}$ & $\mathrm{O}$ & $\mathrm{O}$ & $\mathrm{O}$ \\
\hline
\end{tabular}

